\title{
Acknowledgements and Remarks from the Editor-in-Chief
}

Contemporary Challenges: The Global Crime, Justice, and Security Journal (CCJ) was borne of a realisation that problems of global crime, justice, and security are becoming ever more entangled and pose some of the most trying challenges to modern society. To provide a platform for novel ideas to add to the academic debate surrounding these issues, a select number of postgraduate students from the Edinburgh Law School organised and founded the CCJ.

In choosing the journal's name, the editorial board felt like it had found the most succinct description of its focus while also reflecting its thematic range. Issues of global crime, justice and security manifest in multiple aspects of political and social life which adds to their salience in academic debate.

Before presenting the research of this publication, we would like to dedicate a few lines to the people without whom the CCJ's conception would not have been possible.

First, we would like to express our gratitude to Dr. Andy Aydin-Aitchison, senior lecturer in criminology at the Edinburgh Law School and program director of the MSc in Global Crime, Justice and Security. His insightful classes built the foundation upon which the CCJ was able to flourish. Moreover, his constant encouragement and enthusiasm were motivating ever since the CCJ was just a faint idea in the heads of a handful of venturous students. His willingness to be the CCJ's academic patron is a testimony of his support. It is an honour to have Dr. Aydin-Aitchison co-write the foreword to this issue alongside Dr. Milena Tripkovic and Dr. Andrea Birdsall.

Secondly, we would like to thank Ms Rebecca Wojturska as well as the rest of the Library \& University Collections department of the University of Edinburgh. Ms Wojturska helped us with the registration of the journal, website set-up and the overall establishment of the CCJ, and was 


\section{Vol. 1 September 2020 pp. i-ii}

always available to answer any administrative queries - no matter how mundane they seemed. Her vigorous support paved the way for the current as well as future issues of the CCJ.

Our compliments further extend to the lecturers and staff of the Edinburgh Law School. It was their passion for academic progress that inspired our authors and editors to proactively partake in academic debate.

Furthermore, we would like to acknowledge our authors - the core of our publication - who submitted their excellent manuscripts despite the simultaneous pressure from the COVID-19 pandemic and their own academic commitments.

The journal is divided into two sections: Commentaries and Articles. Commentaries are small pieces in which authors are at the leniency to comment and give their opinion on a particular topic. They aim to provide thought-provoking perspectives rather than holistic analyses. Articles, on the other hand, are longer and more detailed accounts of a given topic. Their aim is to showcase the research done by postgraduate students in the field of global crime, justice and security.

The contemporary challenges that the world confronts should not be taken lightly. We hope that with this modest contribution, we can offer some perspectives to help shape ideas on how to overcome these challenges.

On behalf of the editorial board,

Frederik Florenz

Editor-in-Chief 